\title{
A Study on Comprehensive Analysis and Control of Cost and Progress of Architectural Decoration Engineering from the Angle of Earned Value
}

\author{
Baoping Chen \\ School of Management \\ Wuhan University of Science and Technology \\ Hubei, China
}

\author{
Yang Song* \\ School of Management \\ Wuhan University of Science and Technology \\ Hubei, China \\ 6428995@qq.com
}

\begin{abstract}
On the basis of introduction of the fundamental principles of Earned Value Management and relevant parameters and evaluation indicators, this paper illustrates features of decoration engineering, and aims to discuss the dynamic analysis of cost and progress of decoration engineering with the adoption of Earned Value and further verifies the analysis by means of engineering examples and tables and diagrams. It is suggested that Earned Value Method is an effective way of measuring and controlling cost and pace in engineering project and it also can be applied into real-time analysis of cost and progress of decoration engineering and correction of adverse factors to ensure that the prospective engineering management can be achieved. Accordingly, Earned Value is an advanced technical tool for project management and it qualitatively and quantificationally analyzes the cost and progress of engineering management according to parameters, indices and curve graphs.
\end{abstract}

Keywords-WBS; Earned Value; dynamic control program; decoration engineering

\section{INTRODUCTION}

With the development and segmentation of overall construction industry, architectural decoration engineering has developed into construction decoration industry gradually and it is both one part of full life cycle of construction project and the last construction progress of housing construction. Therefore, the control of cost and progress which is key part of decoration engineering is especially important and optimizing management of cost and progress of decoration engineering is the new subject in perfecting decoration industry presently in China. This paper introduces the principles of Earned Value, and in order to complete the study on comprehensive control of cost and progress of decoration engineering, this paper sets the control of cost and progress of refined decoration engineering of a certain seed company technology building as an example, according to dynamic control program of engineering management and based on Work Breakdown Structure (WBS).

\section{PRINCIPLES OF EARNED VAlue}

\section{A. Development of Earned Value}

The concept of Earned Value originates in the US, firstly used in Polaris Missile Project, and in 1967, United States
Department of Defense formulated systematic guidelines of control of cost-progress and considered Earned Value. The most fundamental element of Earned Value is that project progress is measured via quantity of money instead of engineering quantity, and in this way, the project progress would be reflected by input but engineering achievements transformed from investment, which is a advanced project management technology to control overall cost and progress of management of engineering project construction.

\section{B. Three Fundamental Parameters of Earned Value} (BCWP;BCWS;ACWP)

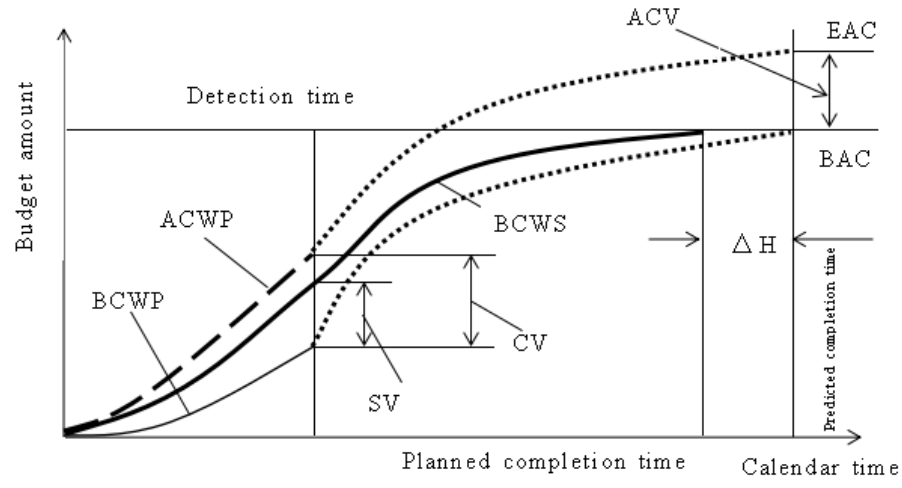

Fig. 1. Diagram of Parameters and Variances in Earned Value

1) Budgeted Cost for Work Performed(BCWP)

Budgeted cost for work performed(BCWP) refers to capital required for work performed wholly or partly in a certain time, taking the approved budget as the standard, also named as earned value.

$$
\text { BCWP }=\text { work performed } \times \text { budgeted cost }
$$

2) Budgeted Cost for Work Scheduled(BCWS)

Budgeted cost for work scheduled(BCWS) refers to capital required for work scheduled wholly or partly in a certain time, taking budget as the standard, also named as planned value.

BCWS $=$ work scheduled $\times$ budgeted cost 
3) Actual Cost for Work Performed (ACWP)

Actual cost for work performed (ACWP) refers to capital required for work performed wholly or partly in a certain time, also named as actual cost.

ACWP $=$ work performed $\times$ actual cost

\section{Four Evaluation Indicators Derived from Three}

Fundamental Parameters(CV;SV;CPI;SPI)

1) Cost Variance(CV)

Cost variance $(\mathrm{CV})$ refers to difference between budgeted cost for work performed and actual cost for work performed at a certain check point.

$\mathrm{CV}=\mathrm{BCWP}-\mathrm{ACWP}$

When cost variance is negative, cost of operating project is beyond the budgeted cost; and when cost variance is positive, expenditure of operating project is cut down so actual cost is within budgeted cost; when cost variance is zero, cost of operating project is in accordance with budgeted cost.

\section{2) Schedule Variance(SV)}

Schedule variance(SV) refers to difference between budgeted cost for work performed and budgeted cost for work scheduled at a certain check point.

\section{$\mathrm{SV}=\mathrm{BCWP}-\mathrm{BCWS}$}

That schedule variance is negative means progress delay; that schedule variance is positive means advanced progress; that schedule variance is zero means actual progress is in accordance with schedule.

\section{3) Cost Performance Index(CPI)}

Cost performance index(CPI) refers to earned value - actual cost ratio.

\section{$\mathrm{CPI}=\mathrm{BCWP} / \mathrm{ACWP}$}

That cost performance index is less than 1 means overexpenditure, i.e., that actual cost is higher than budgeted cost; That cost performance index is more than 1 means underexpenditure, i.e., that actual cost is lower than budgeted cost; That cost performance index is equal to 1 means that actual cost is equal to budgeted cost.

4) Schedule Performance Index(SPI)

Schedule performance index(SPI) refers to earned value planned value ratio.

\section{$\mathrm{SPI}=\mathrm{BCWP} / \mathrm{BCWS}$}

That schedule performance index is less than 1 means progress delay, i.e., that actual progress is behind schedule; That schedule performance index is more than 1 means advanced progress, i.e., that actual progress is ahead of schedule; That schedule performance index is equal to 1 means actual progress is in accordance with schedule.

\section{Extended parameters and Indicator(BAC;EAC;ACV)}

In case the Earned Value is employed in comprehensive control of cost and progress, the tendency that the cost and progress at the end of project can be predicted, based on present variance of cost and schedule and corresponding analysis of cause. In the figure, BAC refers to budget at completion which is estimated upon making the plan; EAC refers to estimate at completion which means estimated cost at completion according to present variance of cost and schedule in the process of implementing; ACV refers to at completion variance. These three parameters satisfy the equation of $\mathrm{ACV}=\mathrm{BAC}-\mathrm{EAC}$

\section{APPLICATION OF EARNED VALUE INTO DECORATION ENGINEERING MANAGEMENT}

Because of one-time construction of architectural decoration engineering and mobile construction work, it is necessary to apply dynamic control program into management of cost and progress of project. The key to control in implementation of project is dynamically grasping cost and progress of engineering, timely finding cost variance and progress delays, and moreover achieving object of project management supported by the study on comprehensive analysis and control of cost and progress of project with the full adoption of principles of Earned Value. This paper sets the control of cost and progress of refined decoration engineering of a certain seed company technology building as an example, and expounds application of Earned Value in engineering management.

\section{A. WBS}

WBS is the deliverable-oriented grouping on project elements and it concludes and defines total scope of project with each descending level of the WBS representing an increasingly detailed definition of the project work. WBS is the heart of planning process, and also the important basis of making schedule and cost budgeting, so it can provide frame for developing control system of cost and progress of project. According to bill of quantities, this paper applies mode of breakdown based on implementation process in segmenting decoration construction procedure to provide basis for subsequent determination of planned value and collection of actual value.

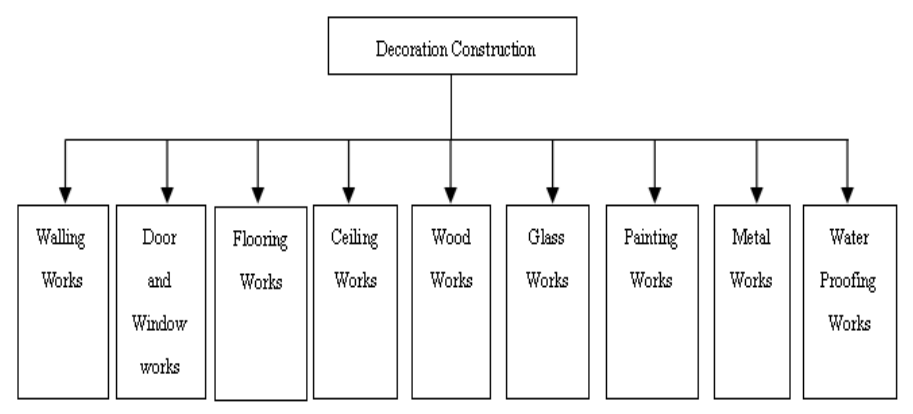

Fig. 2. WBS of Refined Decoration Engineering

\section{B. Planned Value}

Planned value is determined as itemized construction cost in each procedure of refined decoration engineering of the seed company technology building, and it needs to be defined firstly in application of Earned Value. Moreover, planned value generally should not be changed randomly except for modification of contract. In case of changes in cost and 
progress of project in changed contract, the planned value can be changed accordingly with approval.

\section{Dynamic Trace and Control}

This paper sets the refined decoration engineering of the seed company technology building as an example, and applies Earned Value in dynamic trace and control of cost and progress with planned project duration of three months, total decoration areas of $6,675 \mathrm{~m}^{2}$ and total budget of 3,017,458 Yuan. This seed company technology building is equipped with one floor underground and five floors on the ground, with frame structure, and workload chart should be made according to dynamic trace of implementation of project within a month from starting work.

TABLE I. WORKLOAD(A MONTH)

\begin{tabular}{c|c|c|c|c|c|c|c|c|c}
\hline Project name & Walling & $\begin{array}{c}\text { Door and } \\
\text { window }\end{array}$ & Flooring & Ceiling & Wood & Glass & Painting & Metal & $\begin{array}{c}\text { Water } \\
\text { proofing }\end{array}$ \\
\hline Unit & $\mathrm{m}^{2}$ & $\mathrm{~m}^{2}$ & $\mathrm{~m}^{2}$ & $\mathrm{~m}^{2}$ & $\mathrm{~m}^{2}$ & $\mathrm{~m}^{2}$ & $\mathrm{~m}^{2}$ & $\mathrm{~m}^{2}$ & $\mathrm{~m}^{2}$ \\
\hline $\begin{array}{c}\text { Planned } \\
\text { workload }\end{array}$ & 155 & 365 & 2700 & 1600 & 100 & 350 & 2000 & 500 & 50 \\
\hline $\begin{array}{c}\text { Budget unit } \\
\text { price } \\
\text { (Yuan/unit) }\end{array}$ & 90 & 280 & 70 & 85 & 1500 & 320 & 35 & 100 & 80 \\
\hline $\begin{array}{c}\text { Completed } \\
\text { work }\end{array}$ & 155 & 360 & 2500 & 1500 & 100 & 350 & 1950 & 500 & 48 \\
\hline $\begin{array}{c}\text { Actual unit } \\
\text { price } \\
\text { (Yuan/unit) }\end{array}$ & 90 & 290 & 70 & 87 & 1500 & 323 & 35 & 95 & 80 \\
\hline
\end{tabular}

Based on analysis of progress of each working procedure, Earned Value can be employed to analyze the project to figure out data of three fundamental parameters of all project works in the first month as TABLE II.

TABLE II. THE THREE BASIC PARAMETERS OF THE WORK IN THE FIRST 1 MONTHS OF THE PROJECT

\begin{tabular}{c|c|c|c|c}
\hline Code & Workgroup name & BCWP & BCWS & ACWP \\
\hline 001 & Walling works & 13,950 & 13,950 & 13,950 \\
\hline 002 & $\begin{array}{c}\text { Door and window } \\
\text { works }\end{array}$ & 100,800 & 102,200 & 104,400 \\
\hline 003 & Flooring works & 175,000 & 189,000 & 175,000 \\
\hline 004 & Ceiling works & 127,500 & 136,000 & 130,500 \\
\hline 005 & Wood works & 150,000 & 150,000 & 150,000 \\
\hline 006 & Glass works & 112,000 & 112,000 & 113,050 \\
\hline 007 & Painting works & 68,250 & 70,000 & 68,250 \\
\hline 008 & Metal works & 50,000 & 50,000 & 47,500 \\
\hline 009 & Water proofing works & 3,840 & 4,000 & 3,840 \\
\hline & Total & 801,340 & 827,150 & 806,490 \\
\hline
\end{tabular}

Earned value, planned value and actual value in the first month of project will be employed in calculating. Taking decoration ceiling works as the example: BCWP $=$ work performed $\times$ budgeted cost $=1500 \times 85=12,750$ Yuan; BCWS =work scheduled $\times$ budgeted cost $=1600 \times 85=136,000$ Yuan; ACWP =work performed $\times$ actual cost $=1500 \times 87=130,500$ Yuan. It can be suggested in TABLE Ithat the three fundamental parameters in the first month of project are separately: $\mathrm{BCWP}=801,340$ Yuan; $\mathrm{BCWS}=827,150$ Yuan; ACWP=806,490 Yuan; CV=BCWP - ACWP=801,340 $806,490=-5,150<0 ; \quad$ SV=BCWP - BCWS $=-25,810<0$; $\mathrm{CPI}=\mathrm{BCWP} / \mathrm{ACWP}=0.994<1$; SPI $=\mathrm{BCWP} / \mathrm{BCWS}=0.969<1$. The four evaluation indicators derived from three fundamental parameters in earned value can suggest the over-expenditure and progress delays in this project.

\section{Variance Analysis}

Variance analysis refers to analysis according to calculated data by earned value, planned value and actual cost and it can be expressed in different ways in which horizontal line method, tabular method and curve method are commonly used. This decoration project applies tabular form or curve method in comprehensive variance analysis of cost and progress of project. In the progress of implementing project, it is ideal that the three curves of ACWP, BCWS and BCWP rise steadily and are close to each other, i.e., the project is being implemented complying with set plan. If there is ever-increasing variation among three curves, there may be large variance.

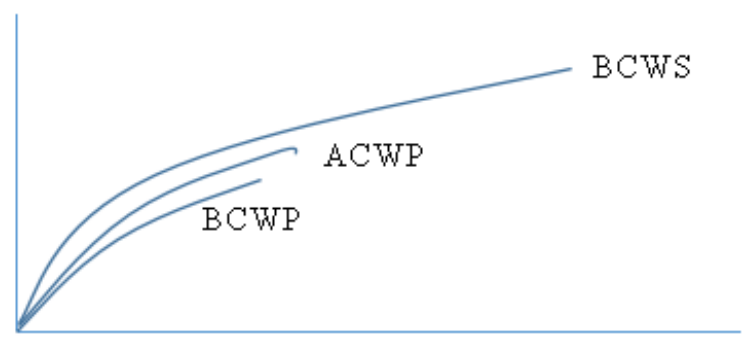

Fig. 3. Diagram of Analysis of Parameters in Earned Value

\section{E. Cause Analysis}

After figuring out three fundamental parameters and four evaluation indicators via Earned Value, it is found out that there are over-expenditure and progress delays. Based on the study on comprehensive analysis and control of cost and progress of architectural decoration engineering from the angle of Earned Value, it is suggested that the five factors leading to variance of cost and progress of decoration engineering are as follows:

\section{1) Rising Prices}

Rising prices of doors \& windows, glass, ceilings and other materials influence engineering cost of project, increase the cost and restrict the control of decoration engineering cost.

\section{2) Design Causes}

After entry, the winning bidder of decoration engineering company failed to timely find technical anomalies or problems of construction quality and to pose the problems to general contractor; general contractor failed to arrange technical disclosure; anomalies or mistakes in decoration drawing design lead to default in later control of cost and progress of project construction.

\section{3) Owner Causes}

Owner proposed to change construction plan and add contents in the progress of construction, and the poor coordination of selecting a certain material with Decoration Company leads to the information distortion, thus rework and finally progress delay. 


\section{4) Construction Causes}

In the progress of decoration, improper selection of construction plan leads to rework and restructure; unqualified materials are used instead of qualified materials and it is investigated and fined by supervising unit; in the wood works, problems arise because of meeting tight deadlines regardless of quality of construction; there is something wrong with work handover between construction procedures and incongruous resource allocation, leading to ineffective connection between point and face; construction scheme and progress scheme cannot satisfy the needs of site construction; lack of builders and mechanical tools and idle labor force influence progress and cost.

\section{5) Objective Causes}

Rising consumer price index leads to rising labor cost, influencing construction cost.

\section{F. Corrective Measures}

Aiming at the causes above and over-expenditure and progress delays, corrective measures can be taken in the following four aspects.

\section{1) Organizational Measures}

It is necessary to employ more efficient staffs and more experienced project manager to improve work efficiency and resource utilization; re-optimize resource on the site and improve supply and coordination of materials to make sure of normal operation of critical works, critical path and critical procedures; in order to shorten construction period, it is necessary to optimize workflow organization and proper crashing and concurrent works can also be carried out, focusing on and monitoring risks; reasonably allocate staffs of different works and entry of construction machinery and materials into the site, improve efficiency of procedure connection, use effectively work face and reinforce self-inspection, mutual inspection and special inspection in the progress of construction; keep execution-tracing file.

\section{2) Management Measures}

Decoration constructors can employ new ways, new technologies and new methods to optimize progress of construction and to significantly improve work efficiency of project engineering; optimize contract management.

\section{3) Technical Measures}

Decoration designers can search for new and more efficient designing scheme to meet the demands of construction technology and working method.

\section{4) Economic Measures}

In case of claims events, it is necessary to timely present claim agreement of intent to general contractor to make up for over-expenditure; dynamically check cost for cost saving; according to market conditions, planned cost should be accounted dynamically and the plan should be adjusted.
Through the measures above, take BCWS as the basis of control in the next stage, improve earned value and decrease cost to achieve the best effect of management of cost and progress.

\section{PRACTICAL APPlications of EARNed VALUE in DECORATION ENGINEERING MANAGEMENT}

In project management, Earned Value is an advanced and effective technical tool, and period of decoration engineering is generally short with low input so managers frequently ignore the influences of dynamic management on cost and progress of decoration engineering construction, leading to overexpenditure and progress delays in the later period. With the development and perfection of decoration engineering, it is necessary to make decoration engineering management more standard and scientific, and furthermore, it is urgent to find effective dynamic monitoring methods, and the application of Earned Value in decoration construction management is also a new exploring. Earned Value overcomes the restriction of traditional single control of cost and progress and studies the comprehensive analysis and control of cost and progress via dynamic control program. In case of failure to attain objective, adjusting the objective dynamically and timely can make sure that control of project cost and plan can be operated as expected, and therefore, the better application of Earned Value in decoration engineering management and project control is necessary, and it is pre-requisite to store the actual data concerning the cost and progress in the application.

\section{CONCLUSION}

In decoration construction management, this paper sets refined decoration engineering project of a certain seed company technology building as the example, applies principles of Earned Value in control of project management of decoration construction and dynamically discovers variances in engineering, and moreover it takes corrective measures timely to finally make sure of achievement of project objectives according to cause analysis.

\section{REFERENCES}

[1] Miao Lixian. Brief Talk the Application of Earned Value in Control of Project Cost and Progress [J].New West (Second Half).2009(1):161162(In Chinese)

[2] Compilation Committee of Exam Books for National A Construction Division Qualification. Project Management of Construction Engineering $[\mathrm{M}]$. Beijing: China Architecture \& Building Press, 2016.(In Chinese)

[3] Luan Junzhang, and Wanzhu Chen. Practical Applications of Earned Value in Projects [J].Contemporary Chemical Industry. 2015(7):15891591.(In Chinese)

[4] Cao Zaiwei. Application of Earned Value in Project Management of Construction Engineering of Universities [J].Value Engineering. 2013(32):68-70. (In Chinese)

[5] Zhao Pengcheng. Application of Earned Value in Project Management [J]. Management Perspective. 2011(24):123-125.(In Chinese) 